\title{
Simple Physical Exercises at Workstation Can Prevent Potential Health Problems among Software Professionals
}

\author{
${ }^{1}$ Mr. Paulraj S, ${ }^{2}$ Dr. Jeyagowri Subash, ${ }^{3}$ Dr. Ananda BB \\ ${ }^{1}$ Principal, Goldfinch College of Nursing, Bangalore, Karnataka, \\ ${ }^{2}$ Principal, Rani Meyyammai College of Nursing, Chidambaram, Tamilnadu, \\ ${ }^{3}$ Associate Professor, Department of General Surgery, Dr. BR Ambedkar Medical College, Bangalore,
}

Karnataka

\section{Introduction}

The computerization of the workplace has increased tremendously over last decade. This information technology revolution has not only created more jobs but also increased the incidence of physical illness. With technological advancement, use of computer becomes a routine activity of many people's daily life. It is an epitome of modern life, being used in every aspect of life. Workers from software profession are prone to develop a lot of health problems due to continuous physical and mental stress of their work. Their routine and repeated actions in handling computers for an extended period of time causes repetitive strain injuries and visual fatigue when they have not followed a proper working posture.

\section{Benefits Of Simple Exercises At Workstation}

- It reduces fatigue

- It improves muscular balance and posture

- It improves muscle coordination

- It assists in correct posture by lengthening tight muscles that pull areas of the body away from their intended position

- Increases blood and nutrient supply to muscles, thereby possibly reducing muscle soreness

- Potential to decrease injury by preparing the muscles for work before activity

- It offer oneself a chance to spend sometime releasing tension physically and mentally

- Even a short amount of time (10 to 15 minutes) of stretching can calm the mind, provide a mental break and give the body a chance to recharge

- It makes a behaviour simpler, which increases their ability

- It improves sense of wellbeing

- It improves bone health

- It reduces the risk of depression

\section{Exercise}

Exercises are a great way to strengthen our eyes, neck, shoulders, upper limbs, hands, and upper back when people sit hours together in front of the computer screen for work. When one's fate is decided to work in front of the computer screen from sunrise to sunset proper exercises are necessary to prevent computer related injuries, which can occur in a person when using computer over a considerable period of time and also may result in long-term disability. The following were some of the exercises recommended for the software professionals:

\section{DO'S AND DONT'S AT COMPUTER WORKSTATION}

DO'S

- Increase the intensity and duration of exercise gradually

- The distance between your eyes and the screen should be more than $40 \mathrm{~cm}$

- Take frequent breaks

- Make a habit of performing stretching exercises at workplace when time permits

- Blink more often

- Minimize glare

- Use proper lighting

- Follow 20-20-20 rule (look 20 feet away for 20 seconds in every 20 minutes of working on the computer) 
- Don't overstretch at office hours

\section{DONT'S}

- Don't let your computer stay open for a whole day or even longer

- Don't use the computer in bed

- Don't use your computer as a dinner campanion

- Don't knock on the keyboard deliberately

\section{TYPES OF SIMPLE EXERCISES PERFORMED AT WORKSTATIONS}

\section{Exercises for the eyes Step-1}

Place the body and the head straight. Rotate the eyes upward and look the ceiling and then rotate downward to look at the ground surface

Step-2

Rotate the eyes left and right slowly to view at objects on both sides

Step-3

Rotate the eyes to view the objects at the right upper side and then to the right lower side. Do the same for the left upper side and $>$ to the left lopwer side

Place the arms in a relaxed state at the lateral aspect of the body. Rotate the head to one side and maintain still for 5 seconds and de 2 he sam for the other side too

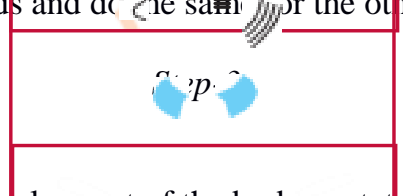

Place the arms in a relaxed state at the later al is juct of the body. $\mid$ ytate the head to the left and maintain still for 5 seconds and do the san $<$ the other side too
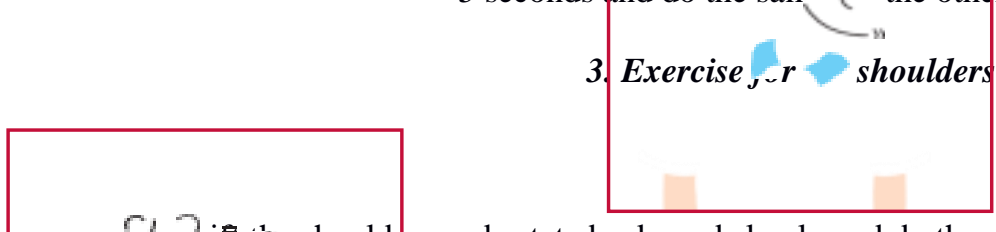

2 Lien 'yly' shoulders and rotate backward slowly and do the same for 10 times at a stretch

\section{Exercises for the upper limbs}

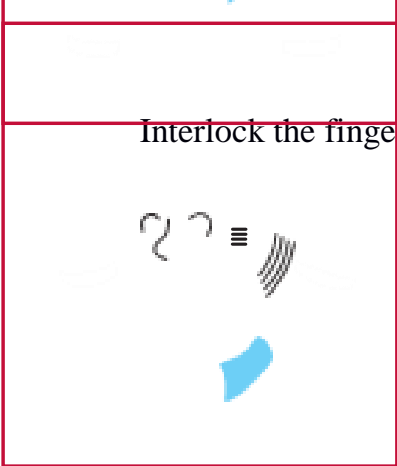



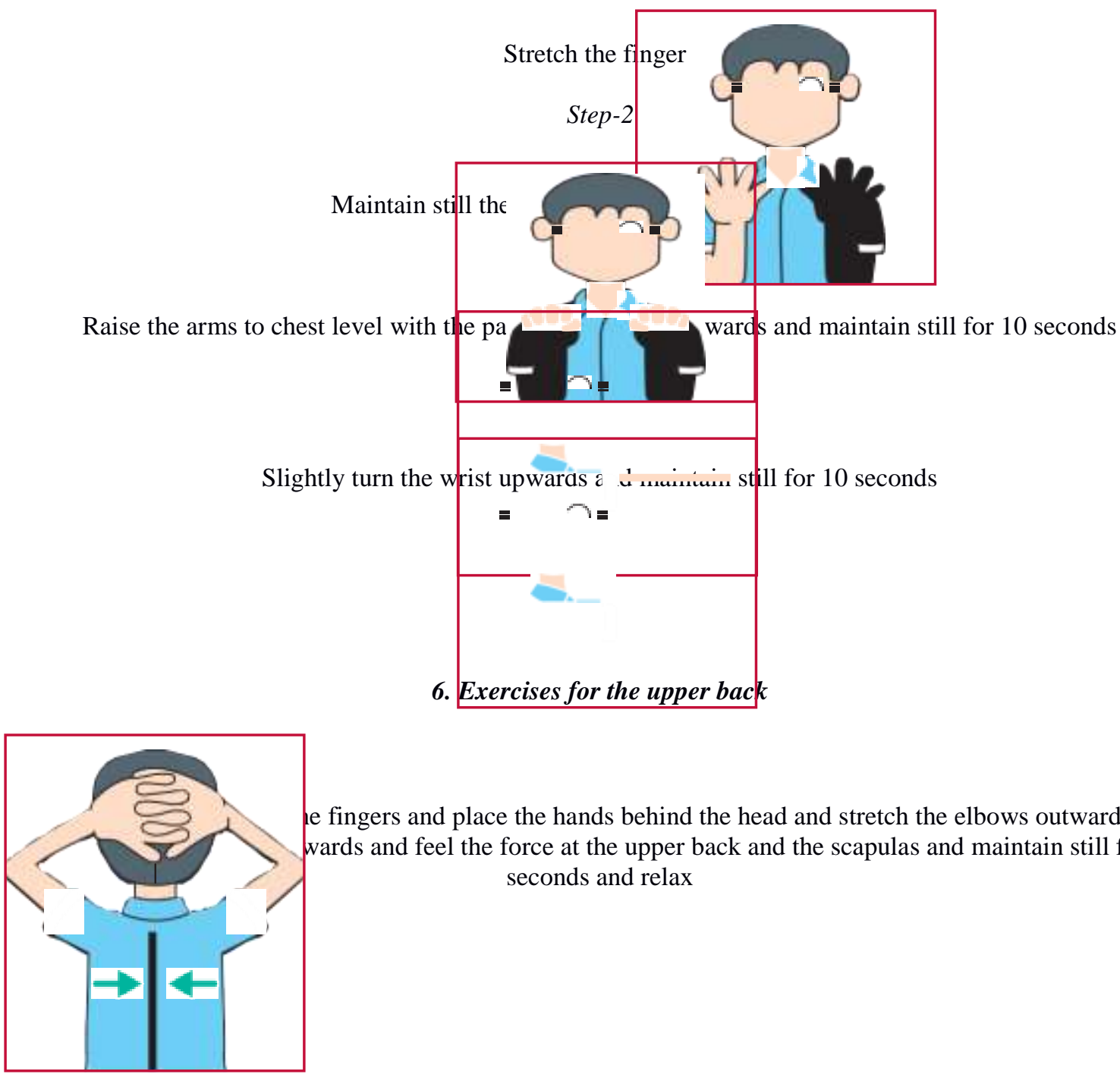

e fingers and place the hands behind the head and stretch the elbows outwards. wards and feel the force at the upper back and the scapulas and maintain still for 5 seconds and relax

\section{Conclusion}

Exercise refers to the physical activity and mental exertion, carried out to maintain physical health and mental fitness. An oft-quoted proverb goes that a sound mind lives in a sound body. There lies a close connection between body and the mind. It is physical exercise which enables us to build a good health which is the key to success. Without doing it we cannot keep healthy. Hence all software professionals should pay due attention to it. Thus, they should aim at maintaining a balance between work, rest and exercise.

\section{References}

[1]. Annesi JJ. Effects of computer feedback on adherence toexercise. Perceptual \& Motor Skills. 1998; 87(2): 723-30.

[2]. Arun Vijay S. Work-related musculoskeletal health disorders among the information technology professionals in India: A prevalence study. IJMRBS 2013;2:118-28.

[3]. Sharma AK, Khera S, Khandekar J. Computer related health problems among information technology professionals in Delhi. Indian J Community Med 2006;31:36-8.

[4]. Mahmoodi F, Sharifian A. The effect of corrective exercises on the degree of pain and shoulder asymmetry (Persian). Research in Sport Rehabilitation. 2014; 2(1): 1-9.

[5]. Buckle PW, Devereux JJ. The nature of work-related neck and upper limb musculoskeletal disorders. Applied Ergonomics. 2002; 33(3): 207-17. 
[6]. Tinubu BM, Mbada CE, Oyeyemi AL, Fabunmi AA. Workrelated musculoskeletal disorders among nurses in Ibadan, South-west Nigeria: A cross-sectional survey. BMC Musculoskeletal Disorders. 2010; 11(1).

[7]. Ranasinghe P, Perera YS, Lamabadusuriya DA, Kulatunga S, Jayawardana N, Rajapakse S, et al. Workrelated complaints of arm, neck and shoulder among computer office workers in an Asian country: prevalence and validation of a risk factor questionnaire. BMC Musculoskeletal Disorders. 2011; 12(1). 